\title{
Vibration isolation for launch of a Space Station orbital replacement unit
}

\author{
Joseph R. Maly ${ }^{\text {a }}$ Joel W. Sills, Jr. ${ }^{b}$ Scott C. Pendleton ${ }^{a}$ \\ George H. James III $^{\mathrm{c}}$ Mark Mimovich ${ }^{\mathrm{d}}$ \\ ${ }^{a}$ CSA Engineering, Mountain View, California \\ ${ }^{\mathrm{b}}$ United Space Alliance, Houston, Texas \\ ${ }^{c}$ NASA/Johnson Space Center, Houston, Texas \\ ${ }^{d}$ CSA Engineering, Albuquerque, New Mexico
}

\begin{abstract}
Delivery of Orbital Replacement Units (ORUs) to on-orbit destinations such as the International Space Station (ISS) and the Hubble Space Telescope is an important component of the space program. ORUs are integrated on orbit with space assets to maintain and upgrade functionality. For ORUs comprised of sensitive equipment, the dynamic launch environment drives design and testing requirements, and high frequency random vibrations are generally the cause for failure. Vibration isolation can mitigate the structure-borne vibration environment during launch, and hardware has been developed that can provide a reduced environment for current and future launch environments.

Random vibration testing of one ORU to equivalent Space Shuttle launch levels revealed that its qualification and acceptance requirements were exceeded. An isolation system was designed to mitigate the structure-borne launch vibration environment. To protect this ORU, the random vibration levels at $50 \mathrm{~Hz}$ must be attenuated by a factor of two and those at higher frequencies even more. Design load factors for Shuttle launch are high, so a metallic load path is needed to maintain strength margins. Isolation system design was performed using a finite element model of the ORU on its carrier with representative disturbance inputs. Iterations on the model led to an optimized design based on flightproven SoftRide MultiFlex isolators. Component testing has been performed on prototype isolators to validate analytical predictions.
\end{abstract}

Keywords: launch vibration isolation, orbital replacement unit, complex stiffness testing, viscoelastic damping

\section{SUMMARY}

The Mobile Transporter Linear Drive Unit (LDU), shown in Figure 1, is a Space Station ORU that is available for launch on the Space Shuttle prior to the 2010 completion of Station construction. Launch vibration-isolation hardware for this ORU was built and tested to provide an environment that is less severe than its qualification environment.

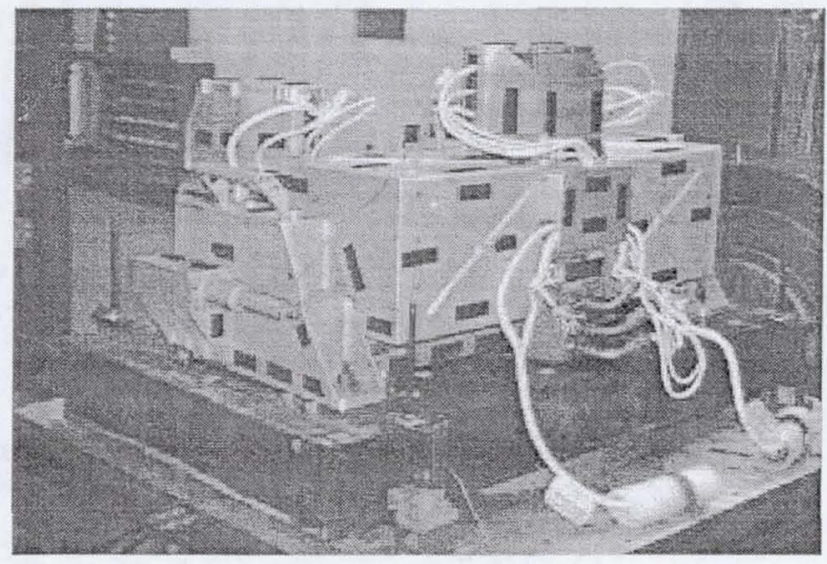

Figure 1. Linear Drive Unit qualification article
Analysis had shown that the LDU has its qualification requirements exceeded due to high frequency random vibrations in the current launch configuration. The isolator design was a variation of the SoftRide MultiFlex Isolator developed by CSA Engineering for whole spacecraft launch isolation. The isolators are shown to attenuate random vibration levels at $50 \mathrm{~Hz}$ by a factor of two and those at higher frequencies even more. Testing of prototype isolators has validated the analysis, and the LDU isolation system will provide an acceptable ORU launch environment. Other ORUs destined for delivery to orbit are expected to benefit from this capability. Furthermore, the isolators developed for Space Shuttle should be applicable to the next generation launch vehicles. 


\section{DRAFT 040222}

\section{DESCRIPTION OF ORBITAL REPLACEMENT UNIT}

The LDU provides drive and stopping forces for the ISS Mobile Transporter (MT) along the Integrated Truss Structure rail. It mounts to the MT primary structure with four ORU attachment bolts. The LDU assembly contains translation drive mechanisms, Engagement/Disengagement (E/D) drive mechanisms, a bogie assembly, a booster foot assembly, a structure assembly, Extra Vehicular Activity (EVA) override cams and launch locks. Additionally, the LDU contains two independent translation drive mechanisms, one primary and one redundant. Each translation drive contains an Integrated Motor and Controller Assembly (IMCA), a gear train, a preload spring assembly, a brake assembly, and a 12inch-diameter drive wheel with an elastomer tire. The LDU is also equipped with thermal control provisions (electric heaters, RTDs, thermostat circuits, and thermal blankets) to keep the IMCAs and other critical mechanisms within the desired operating temperature range.

During launch, launch locks secure the LDU to withstand launch loads and vibration. EVA is required to release the launch locks once the MT is deployed on orbit. The EVA cams allow the astronauts to disengage both translation drive

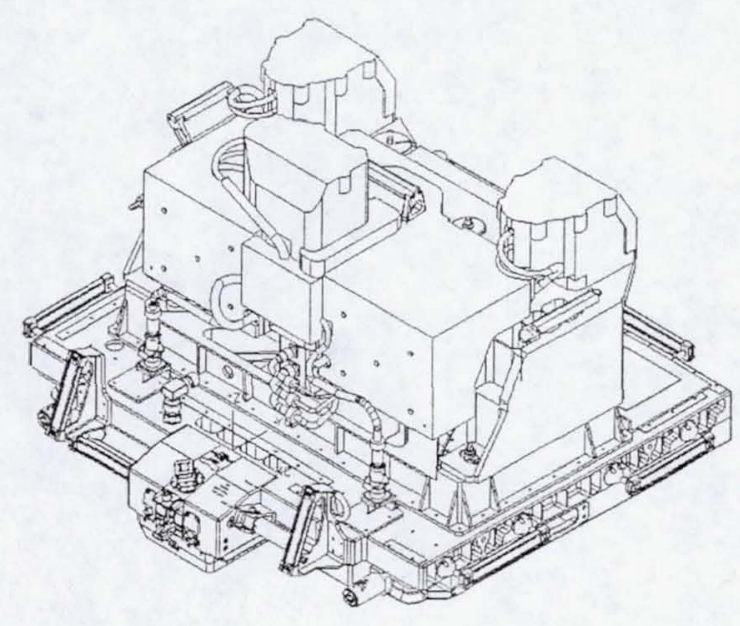

Figure 2. LDU Flight Support Equipment installation kit mounted on adapter plate wheels for EVA removal and replacement of the LDU, if the E/D drives are unable to disengage the translation drive wheels.

The LDU Flight Support Equipment (FSE) Integrated Assembly, shown in Figure 2, consists of the LDU, the LDU FSE, and the Small Adapter Plate Assembly. The Integrated Assembly is used to support transportation of LDU ORUs from earth to orbit, cargo transfer to the on-orbit portion of the ISS, and return from orbit to earth. When the Integrated Assembly is used with the proper carrier or storage platform, the Integrated Assembly can be used to support storage of the LDU at on-orbit ISS external payload sites. The LDU FSE provides a mechanical and structural interface between the LDU ORU and the Adapter Plate. It is composed of interface mounting hardware, a heater system, EVA and Extravehicular Robotics (EVR) aids, and two passive thermal control options.

\section{LDU QUALIFICATION TESTING AND LAUNCH ENVIRONMENTS}

The qualification LDU underwent random vibration testing in June and July 1998[2][3]. Testing was started with nominal random vibration spectra of $10.9 \mathrm{~g}$ RMS $(20-2000 \mathrm{~Hz})$. X and Y axis testing of the unit, including development of notches, was completed without incident. During Z-axis qualification testing, an over-test condition occurred which damaged the unit. At this time, several changes were made to the test procedure. An over-range accelerometer was added to the test setup, with the controller set to abort the run if input to the LDU exceeded a predetermined value. An observer was put in voice contact with the test operator so that the observer could abort the test if any anomaly was observed. And, to minimize the risk of additional damage, the baseline random vibration spectrum was changed to $4.9 \mathrm{~g}$ RMS with reduced levels between 60 and $220 \mathrm{~Hz}$.

Re-qualification-testing took place in November 1998. During this test sequence, notched spectra were redeveloped. Individual axis notched qualification spectra were created using predicted maximum flight level criteria of $2.4 \mathrm{~g}$ RMS, shown in

Figure 3. LDU qualification notched spectra were created with minimum notch levels based on this $2.4 \mathrm{~g}$ RMS level. Results of the qualification testing showed three exceedance areas outside the notches. These exceedances occurred for accelerometers on the primary E/D IMCA at $165 \mathrm{~Hz}$ and $1000 \mathrm{~Hz}$ and the brake at $110 \mathrm{~Hz}$. Figure 3 also displays the qualification and acceptance levels for the IMCAs, which are the sensitive components of interest on the LDU. 


\section{DRAFT 040222}

The LDU Integrated Assembly has been designed to fly on two Shuttle carriers, the Integrated Cargo Carrier (ICC) or the Lightweight MPESS Carrier (LMC). Random vibration environments have been developed for the both of these carriers at the adapter-plate interface. These environments are shown in Figure 3. Comparisons of both the LMC and ICC base input spectra to the LDU qualification notched spectrum show that the carrier spectra inputs in the 100 to 400 $\mathrm{Hz}$ range are much greater. This comparison raised concerns that the original qualification certification for the LDU may be exceeded when launched on the common carriers. Therefore, the ISS External Carriers Office initiated a study to develop vibration isolation concepts to provide an acceptable LDU environment that is no more severe than its qualification environment.

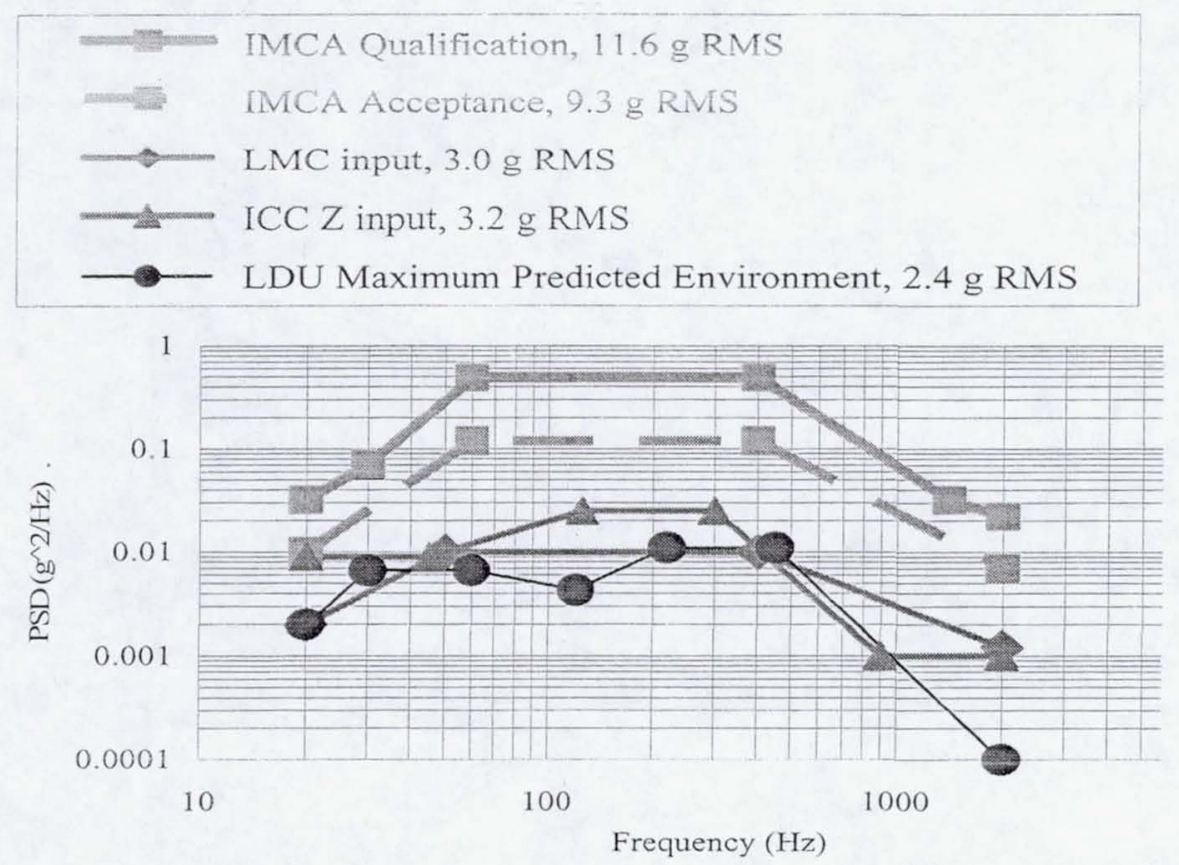

Figure 3. Integrated Cargo Carrier and Lightweight MPESS Carrier inputs,

LDU Maximum Predicted Environment, and IMCA qualification and acceptance levels

In addition to the random environments, quasi-static design load factors for this location in the Shuttle are $13 \mathrm{~g}$ in three coordinate axes applied simultaneously. This load factor specification envelopes both the LMC and the ICC environments for a cargo item with an equivalent mass of the LDU integrated assembly. 


\section{DRAFT 040222}

\section{VIBRATION ISOLATION DESIGN}

Vibration isolation concepts were evaluated with the finite element model developed by Boeing. The LDU is mounted to the Carrier through the FSE and the SAPA, and each component is modeled in detail, as shown in Figure 4. Isolation system performance was evaluated by driving the model with the ICC and LMC random vibration spectra, and recovering acceleration PSD responses at the critical IMCA components. Initially, isolation was considered at both interfaces, i.c., between the LDU and FSE, and between the FSE and adapter plate. Base inputs were applied and acceleration responses at the IMCAs were computed. Much better attenuation was achieved with the isolation installed at the LDU/FSE interface; in fact, some response levels increased with the isolation at the FSE/SAPA interface.

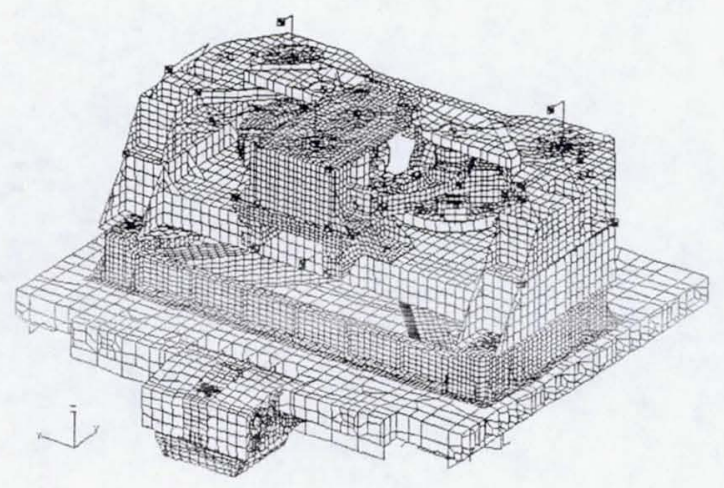

Figure 4. Finite element model of LDU FSE installation kit

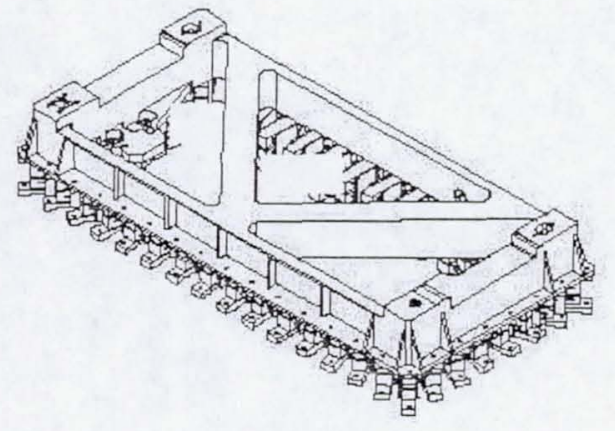

Several isolation configurations were evaluated at the LDU/FSE interface. For configurations determined to be effective, detailed isolation system models were built and integrated with the system model. Very good response reductions were achieved with a derivative of the SoftRide MultiFlex Isolation system described in Reference [4]. This isolation system is a set of forty-four $6 \mathrm{Al} 4 \mathrm{~V}$ Titanium flexures with viscoelastic constrained layer damping. Figure 5 shows the isolators installed below the FSE, at the bolt locations where the FSE mounts to the adapter plate. The MultiFlex isolation provides flexibility and damping in three orthogonal axes between the launch vehicle and the satellite, so dynamic launch loads with both axial and lateral components can be mitigated.

Figure 5. MultiFlex isolators installed below LDU FSE

In parallel with performance analysis, isolator strength was evaluated. The detailed isolator finite element model was reduced to a matrix formulation (Nastran DMIG) with boundary nodes at the top and bottom of the isolator. This DMIG formulation represents the mass, stiffness, and damping of the isolator. The DMIG reduced model was replicated at all isolator locations in the system model shown in Figure 4. The model was then subjected to the quasi-static load factors of $13 \mathrm{~g}$ in each of three coordinate directions simultaneously, and interface forces were recovered at the isolator boundaries. Worst-case forces and moments for a single isolator were then determined based on three criteria: maximum forces, maximum shears, and maximum moments. The worst-case loads for each criterion were then applied to the detailed isolator model, and displacements and von Mises stresses were recovered. The maximum von Mises stress was found to be $60.6 \mathrm{ksi}$, a healthy margin on the $6 \mathrm{Al} 14 \mathrm{~V}$ yield strength of $120 \mathrm{ksi}$, and the maximum displacement across one flexure was 0.16 inches.

\footnotetext{
"Six launches have demonstrated SoftRide isolation to date, and MultiFlex systems have flown twice. Coupled loads analyses and flight telemetry data showed that the SoftRide systems performed as expected and greatly reduced dynamic launch loads for the spacecraft.
} 


\section{DRAFT 040222}
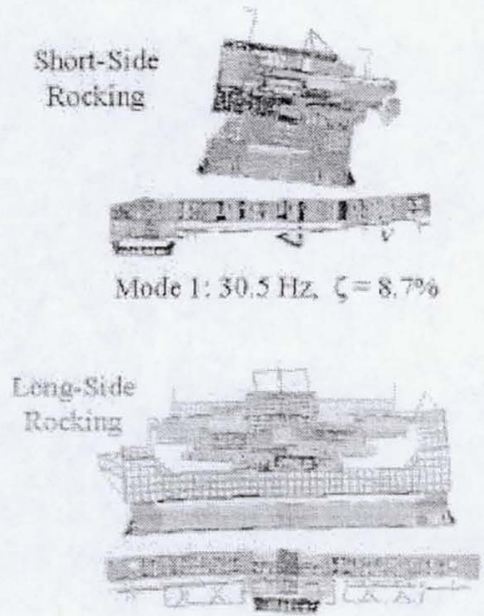

Mode $2: 35.4 \mathrm{~Hz}, \zeta=8.0 \%$

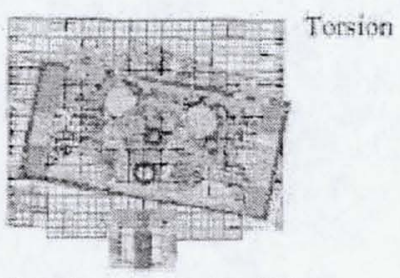

Mode $3: 46.0 \mathrm{~Hz}, \zeta=7,7 \%$

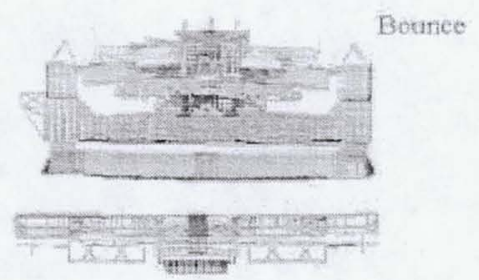

Mode 4: $46.7 \mathrm{~Hz}, \zeta=12.6 \%$

Figure 6. Primary modes of isolated LDU as predicted by finite element model

\section{ISOLATION PERFORMANCE PREDICTIONS}

Analysis results with the SoftRide Isolation system showed very good attenuation when subjected to both the ICC and LMC random vibration inputs. A typical response acceleration power spectral density (PSD) plot due to the ICC random vibration input is shown in Figure 7, for X-direction input and X-direction responses at the Primary Engagement/Disengagement IMCA. The un-isolated response is shown for comparison. Isolated responses were computed with the viscoelastic material evaluated at four discrete temperatures $\left(45^{\circ}, 60^{\circ}, 80^{\circ}\right.$, and $\left.100^{\circ} \mathrm{F}\right)$ and at three frequencies $(25,40$, and $90 \mathrm{~Hz})$ to capture the temperature-frequency variations in the isolator stiffness and damping. The IMCA qualification and acceptance spectra are included for reference. Similar plots for X and $\mathrm{Y}$ inputs and responses are shown in Figure 8.

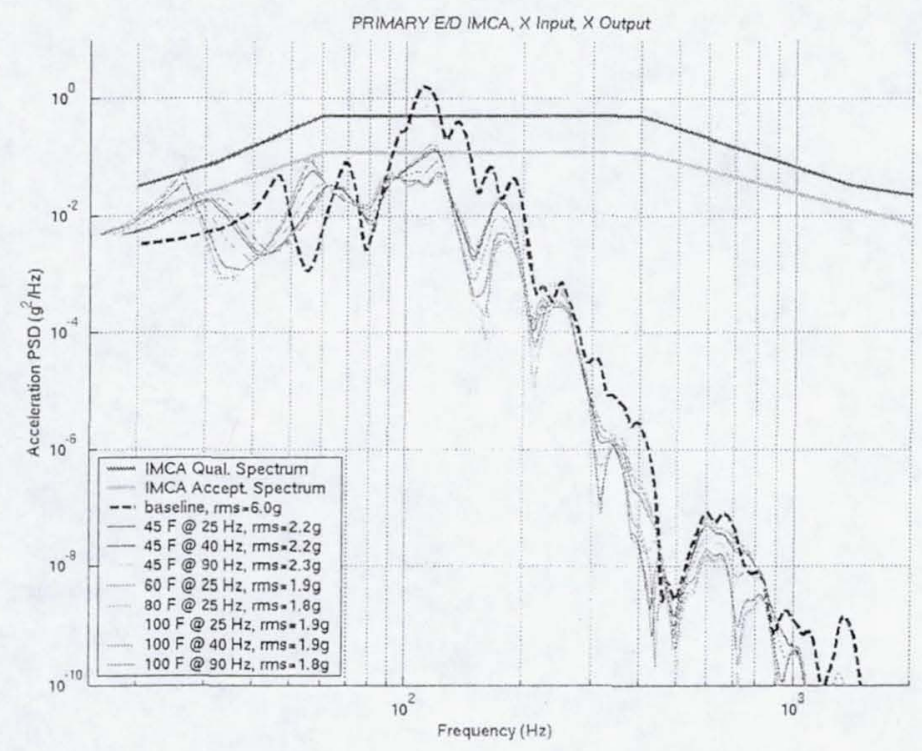

Figure 7. $\mathrm{X}$ response at primary E/D IMCA with and without isolation; isolation system evaluated between $45-100 \mathrm{~F}$ and between 25 and $90 \mathrm{~Hz}$ 


\section{DRAFT 040222}
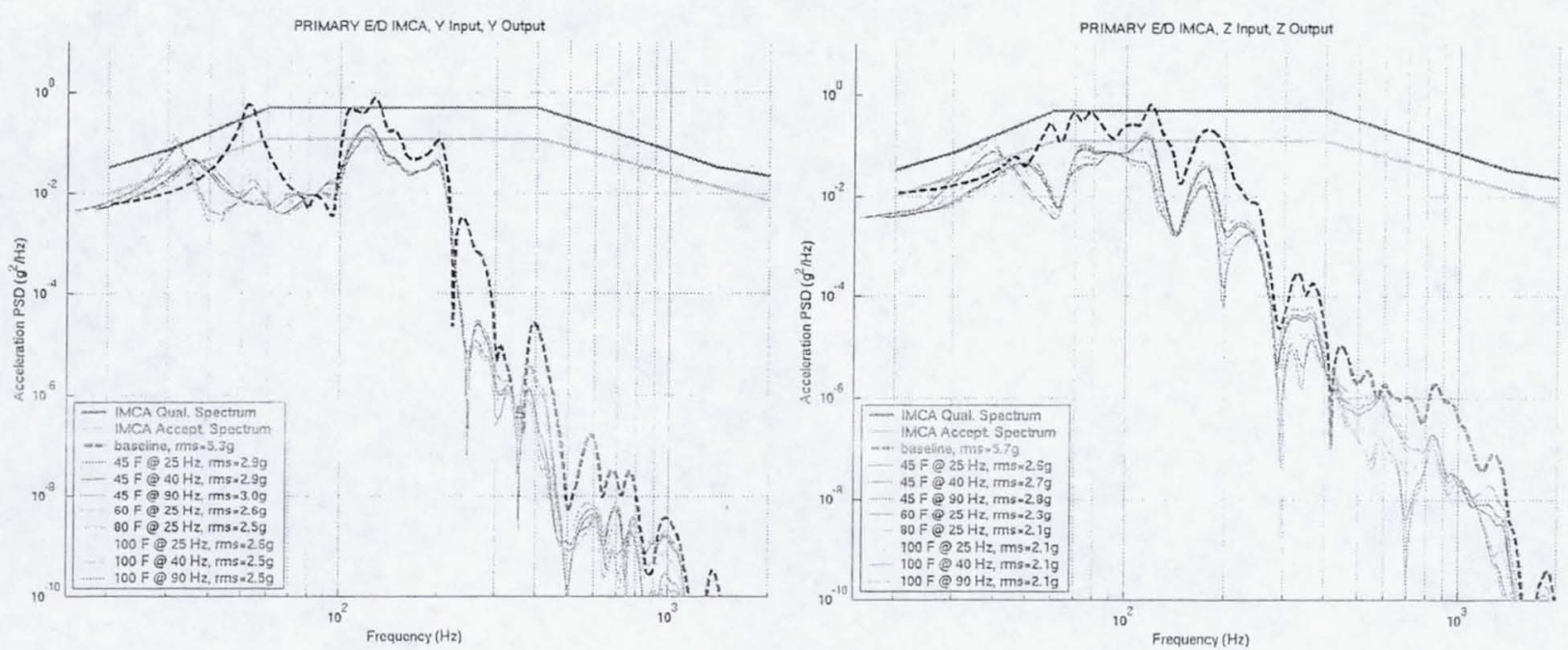

Figure 8. $\mathrm{Y}$ and $\mathrm{Z}$ responses at primary $\mathrm{E} / \mathrm{D} \mathrm{IMCA}$ with and without isolation; isolation system evaluated between $45-100 \mathrm{~F}$ and between 25 and $90 \mathrm{~Hz}$

\section{ISOLATION SYSTEM TESTING}

To qualify the SoftRide system for flight, each isolator will be tested for performance and strength. Performance testing will consist of Direct Complex Stiffness (DCS) measurements [5], to characterize the component for stiffness and damping. For strength testing, uniaxial forces will be applied independently in each of three directions, and moments will be applied independently for each of the three coordinate directions.

At the time of this writing, DCS measurement of an Engineering Development Unit (EDU) isolator has been completed. The component finite element model was validated with this test, and upon fabrication of the flight units, the performance of each isolator will be measured and shown to be within predicted stiffness values $\pm 10 \%$. DCS measurements will also be used to evaluate the qualification isolators after exposure to the qualification loads.

Qualification tests will be performed to verify strength margins. Acceptance testing will be performed, with flight limit loads, on each of the flight isolators. Figure 9 shows a MultiFlex Isolator under test, in a configuration for both performance and strength testing, for axial loading of the Isolator. Lateral loading is achieved by testing two isolators in parallel.
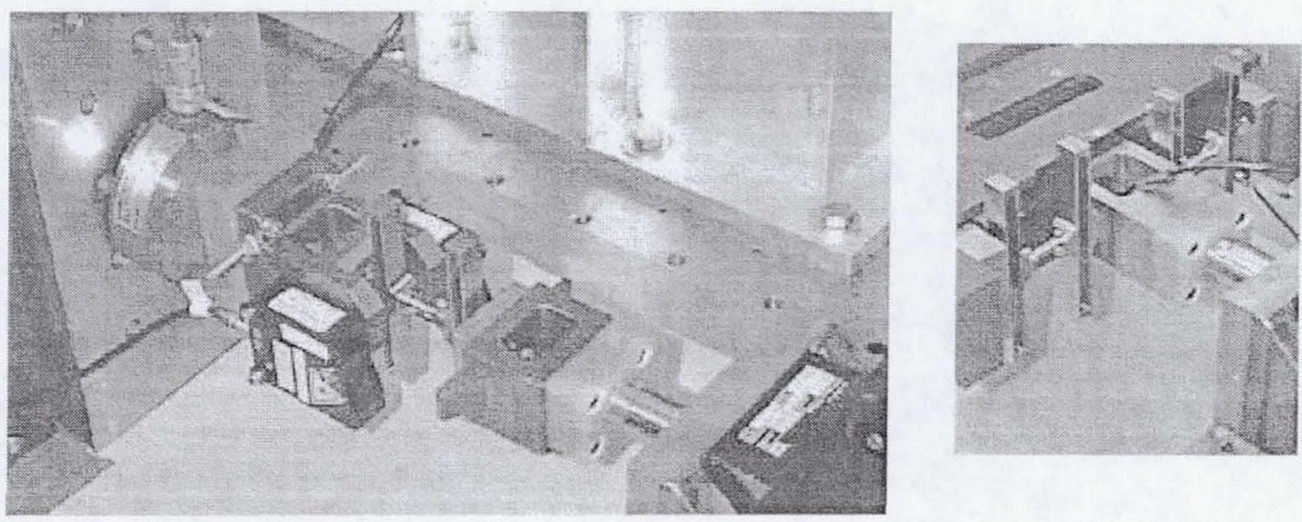

Figure 9. Direct complex stiffness test of MultiFlex isolator 


\section{DRAFT 040222}

\section{CONCLUSION}

An isolation system has been configured to protect an ISS Orbital Replacement Units during launch on the Space Shuttle. Analysis had shown that this ORU in its standard launch configuration had its qualification and acceptance requirements exceeded due to high frequency random vibrations. The isolation system consists of an array of MultiFlex. style isolators, based on a patented design developed by CSA Engineering for whole spacecraft launch isolation. This system is expected to attenuate launch random vibration levels at $50 \mathrm{~Hz}$ by a factor of two and those at higher frequencies even more, and provide an acceptable ORU environment that is no more severe than its qualification environment. Other ORUs destined for delivery to orbit are expected to benefit from this capability. And SoftRide isolators developed for Space Shuttle are expected to be applicable to the next generation launch vehicles.

\section{ACKNOWLEDGMENTS}

The authors acknowledge contributions from and express their gratitude to the ISS External Carriers Office for the opportunity to participate in the development of vibration isolation solutions for the ISS external cargo items.

\section{REFERENCES}

1. Maly, J.R., Sills Jr., J.W., Wilke, P.S., Vibration Isolation for International Space Station External Cargo Items, International Modal Analysis Conference, IMAC-XX, Orlando, Florida, February, 2002.

2. Reports, Structural Analysis, Segment S0 Structural Test Article Acoustic Qualification Testing, MDC 99 H0362.

3. Hoyt, D., Test Report for Vibration Testing of the Qualification Linear Drive Unit (LDU) S/N 099, TR-6069-037, August, 1999.

4. Wilke, P.S., Johnson, C.D., Fosness, E.R., Whole-Spacecraft Passive Launch Isolation, Journal of Spacecraft and Rockets, Vol. 35, No. 5, pgs 690-694, September-October 1998.

5. Maly, J.R., Bender, K.A., Pendleton, S.C., Complex Stiffness Measurement of Vibration-Damped Structural Elements, International Modal Analysis Conference, IMAC-XVIII, San Antonio, Texas, February, 2000. 